\title{
Avascular Necrosis of Femoral Head Following Iliopsoas Tendon Rupture in a Young Female Gymnast
}

\section{Genç Kadın Jimnastikçide İliopsoas Tendon Rüptürü Sonrası Gelişen Femur Başı Avasküler Nekrozu}

\author{
Çiğdem Bayır ${ }^{1}$, İsmail Kaya ${ }^{1}$, Ayşe Livanelioğlu², Bülent Ülkar ${ }^{1}$ \\ ${ }^{1}$ Sports Medicine Department, Faculty of Medicine, Ankara University, Ankara, Turkey \\ ${ }^{2}$ Faculty of Health Sciences, Physical Therapy and Rehabilitation, Hacettepe University, Ankara, Turkey
}

Ç. Bayır

0000-0002-4655-5680

\section{İ. Kaya}

0000-0002-2151-871X

\section{A. Livanelioğlu 0000-0003-0945-1388 \\ B. Ülkar \\ 0000-0002-4656-8705}

Geliş Tarihi/Date Received: 01.02.2019

Kabul Tarihi/Date Accepted: 04.10.2019

Yayın Tarihi/Published Online: 04.11.2019

Yazışma Adresi /

Corresponding Author:

Çiğdem Bayır

Ankara Üniversitesi Tıp

Fakültesi, Spor Hekimliği

Anabilim Dalı, Ankara, Turkey

E-mail:

cigdembayir@hacettepe.edu.tr

(C2020 Türkiye Spor Hekimleri Derne ği. Tüm hakları saklıdır.

\section{ABSTRACT}

The multifactorial nature of hip pain in youngsters may complicate the diagnosis and treatment. There are many possible causes of hip pain in athletes. A careful clinical assessment is needed to eliminate the numerous possibilities, especially when the symptoms cannot to be easily classified into one of the commonly defined clinical entities. Labral pathologies, degenerative disease of cartilage and morphological disorders causing labral pathologies, such as dysplastic hip, slipped capital femoral head and Legg-Calve-Perthes (LCP) disease are the leading pathologies among them. These disorders may present with early onset of hip pain. Although athletic injuries of the hip are less common, rehabilitation takes rather longer times. Thus, an accurate diagnosis and well-organized treatment plan are critical. Imaging methods, careful physical examination and provocative tests are helpful in making a correct diagnosis and delivering a successful treatment. In this case report, the diagnostic and treatment processes of avascular necrosis of femoral head developed following acute rupture of iliopsoas tendon in a young female rhythmic gymnast has been presented.

Keywords: Athletic injuries, hip pain, avascular necrosis

\section{Öz}

Gençlerde kalça ekleminde ağrı ile kendini gösteren sorunlar multifaktöriyel olup tanı ve tedavileri karmaşıktır. Sporcularda kalça ağrısının olası birçok nedeni vardır. Semptomlar genellikle tek bir klinik antite ile bağdaştırılamadığından, çok sayıda olasılığı eleyebilmek için dikkatli bir klinik değerlendirme gerekir. Dejeneratif kıkırdak hastalıkları ile morfolojik bozukluklar labral patolojilere neden olur. Displastik kalça, femur başı kayması, Legg-Calve-Perthes (LCP) gibi patolojiler bu hastalıkların başlıcalarındandır. Bu hastalıklarda genç yaşta görülen kalça ağrısı ortaya çıkmaktadır. Sporcularda kalça yaralanması daha nadir olsa da rehabilitasyonu uzun zaman almaktadır. Bu nedenle doğru tanı ve iyi planlanmış tedavi kritik öneme sahiptir. Görüntüleme yöntemleri, muayene bulguları ve provokatif testler, doğru tanı ve başarılı tedavi için elzemdir. Bu olgu sunumunda genç kadın ritmik jimnastik sporcusunda akut iliopsoas tendon rüptürü sonrasında gelişen femur başı avasküler nekrozunun tanı ve tedavi süreci irdelenmektedir.

Anahtar sözcükler: Spor yaralanmaları, kalça ağrısı, avasküler nekroz

Available at: http://journalofsportsmedicine.org and http://dx.doi.org/10.5152/tjsm.2020.173

Cite this article as: Bayir C, Kaya I, Livanelioglu A, Ulkar B.Avascular necrosis of femoral head following iliopsoas tendon rupture in a young female gymnast. Turk $J$ Sports Med. 2020;55(2):165-71. 


\section{GíRiș}

Genç sporcuda kalça ağrısı bu yaş grubundan beklenen aktivite çeşitliliği nedeniyle önemlidir. Özellikle kalça morfolojisi normal sınırların dışında olan genç sporcularda kalça yaralanmalarının görülmesi ve ilerleyici hasar oluşma riski daha yüksektir. Bu nedenle genç sporcularda kalça semptomlarının özellikle kasık ağrısının dikkatle ele alınması gerekir (1-3).

Kalça ekleminde benzer bulgular gösteren farklı tablolar görülebildiği için kesin tanı gecikebilmektedir. İntraartiküler veya ekstraartiküler kaynaklı patolojilerin ortak semptomu kalça ağrısıdır. Ayırıcı tanı klinik testler ve radyolojik tetkiklerle mümkündür (3).

Femur başı avasküler nekrozu tedavisinin temel amacı eklem ağrılarının giderilmesi, hareket açıklığının sağlanması, normal femur asetabulum ilişkisini koruyarak ileri yaşlarda ortaya çıkabilecek kalça dejenerasyonunun önüne geçilebilmesidir $(4,5)$.

Kalça ağrısı ile kliniğimize başvuran genç ritmik jimnastik sporcusunda iliopsoas tendon rüptürü sonrasında gelişen femur başı avasküler nekrozu sunulmuştur.

\section{OLGU}

13 yaşında ritmik jimnastik ile uğraşan kadın sporcu, sağ kalça ağrısı nedeniyle kliniğimize başvurmuştur. 6 ay önce antrenmanda kalça fleksiyonu sırasında ses geldiğini, sonrasında yakınmalarının başladığını belirtmiştir. Başvurduğu sağlık kuruluşunda kırık olabileceği, bir ay dinlenmesi gerektiği söylenmiştir. Bir ay sonra antrenmanlara yeniden başladığında ağrılarının artması nedeniyle gittiği sağlık kuruluşunda ultrasonografi (USG) yapılmış, hastanın sağ iliopsoas tendonunda $30 * 15 * 7 \mathrm{~mm}$ boyutlarında rüptür saptandığı rapor edilmiş, ancak görüntülerine ulaşılamamıştır.

Fiziksel muayenede; sağ kalça eklem hareket açıklığı (EHA) tam, kas kuvveti sağ tarafta azalmış, zorlu kalça fleksiyonunda ağrı bulunmuştur. Palpasyonla inguinal kanalın proksimali ve distalinde hassasiyet alınmıştır.

Olgumuzdan radyografik görüntüleme istenmiş, femur başı ve asetabulum görüntüsü normal olarak yorumlanmıştır (Şekil 1). Tedavi sırasında olgumuza 10 gün boyunca günde iki kez $400 \mathrm{mg}$ antiinflamatuar (ibuprofen) verilmiştir

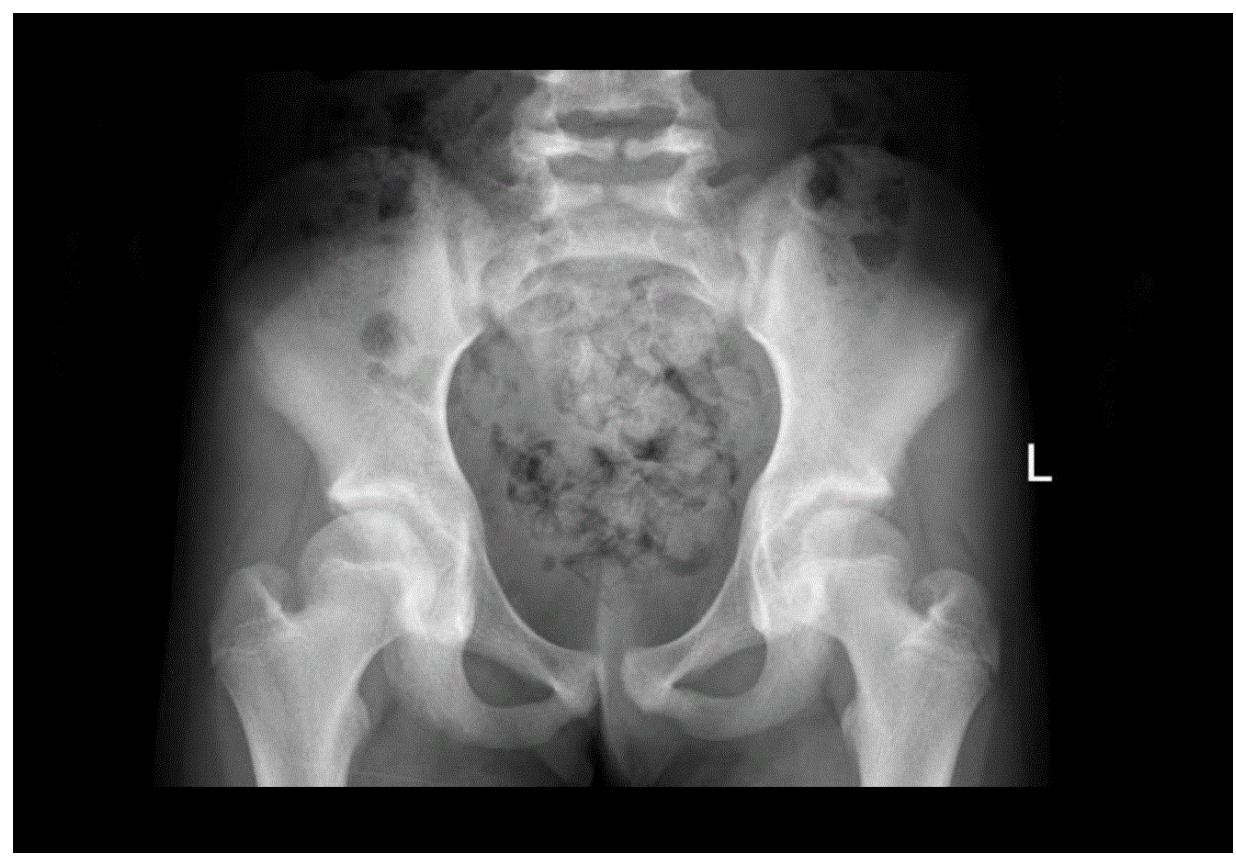

Şekil 1. İlk muayene sonrası çekilen pelvis grafisi 
Sporcu 6 hafta süreyle iliopsoas tendon rüptürü nedeniyle kliniğimizde tedaviye alınmıştır. Tedavide alt ekstremite için kalça ve diz EHA egzersizleri, kalça fleksörleri, ekstansörleri, abdüktör ve addüktörleri ve rotatörlerine yönelik izometrik egzersizler, (herbiri 5'er dk) havuzda öne geriye ve yan yürüme egzersizleri (her yöne 5'er dk) uygulanmıştır. Hareket sırasında ortaya çıkan ağrıda değişiklik gözlenmemesi nedeniyle olgumuz 5 ay sonra tekrarlanan röntgen ve MR görüntüleme ile ortopedi kliniğine yönlendirilmiştir (Şekil 2). Değerlendirmeler sonucunda ortopedi kliniğinde femur başı avasküler nekrozu tanısı ile osteotomi ameliyatı yapılmıştır.
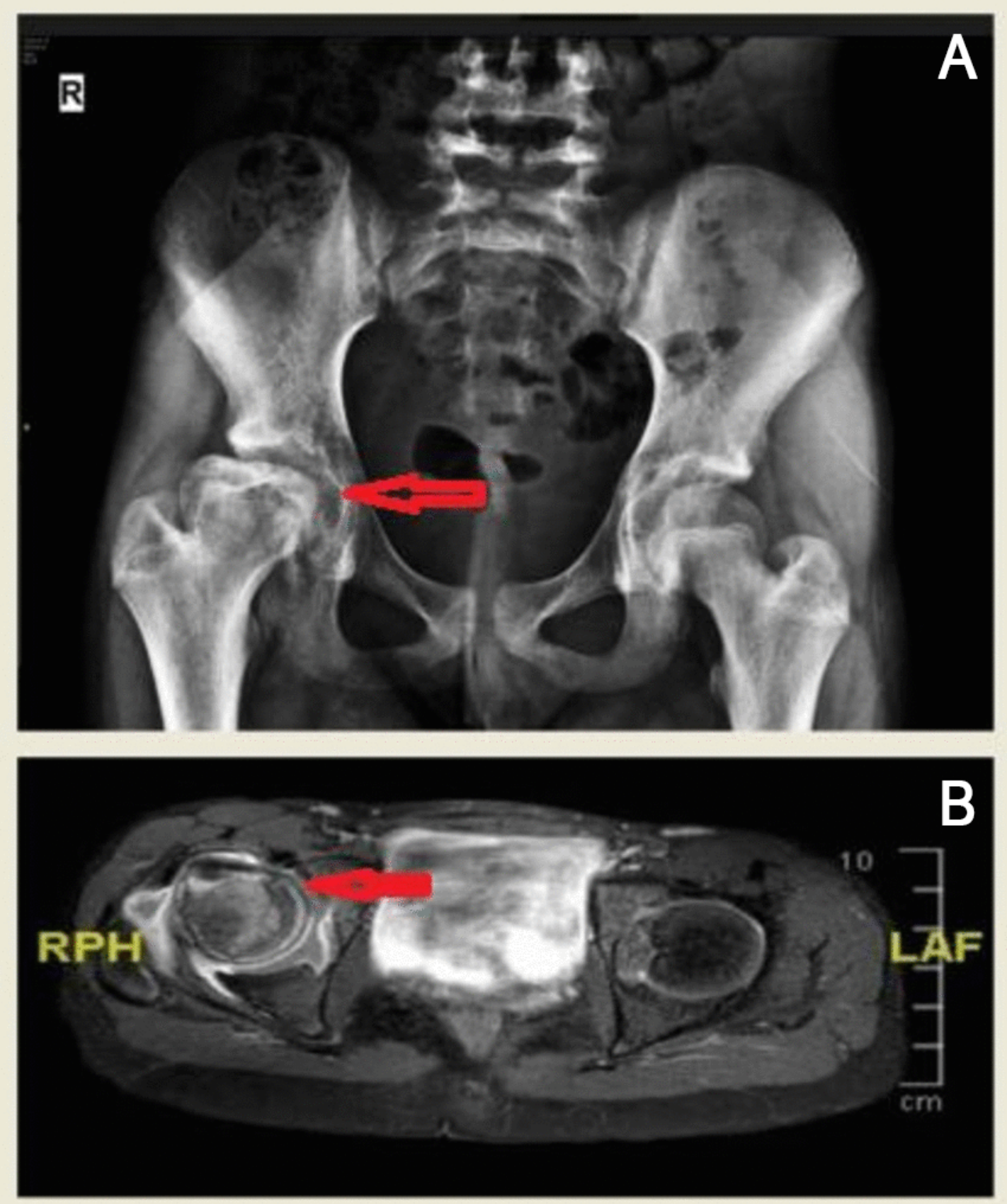

Şekil 2. Olgunun 5 ay sonraki direkt grafi (A) ve MR (B) görüntüleri. Kırmızı ok başları femur başı avasküler nekrozuna ait görüntüleme bulgularını işaret etmektedir. 
Ameliyat sonrası 3. haftadan itibaren kalça kaslarına (kalça fleksörleri, ekstansörleri, abdüktör ve addüktörleri ve rotatörleri) yönelik izometrik kuvvetlendirme (her yöne 5'er dk) egzersizleri uygulanmıştır.
6 hafta süreyle sağ kalça üzerine ağırlık aktarmadan çift koltuk değneği ile mobilize olan sporcunun tedavi öncesi değerlendirmeleri tekrarlanmıştır (bacak çevresi, ekstremite uzunluğu, EHA ve kas kuvveti değerlendirmeleri) (Tablo1-4).

Tablo 1. Operasyon sonrası uygulanan rehabilitasyondan önce ve sonraki bacak çevre ölçümleri

\begin{tabular}{lllll}
\hline & SAĞ [cm] & \multicolumn{3}{c}{ SOL [cm] } \\
\cline { 2 - 5 } & TEDAVİ & TEDAVI & TEDAVI & TEDAVi \\
& ÖNCESI & SONRASI & ÖNCESI & SONRASI \\
$\mathbf{3 0}$ & 49,5 & 45 & 46,2 & 47 \\
$\mathbf{3 5}$ & 47,5 & 43 & 44 & 44 \\
$\mathbf{2 0}$ & 40,5 & 39 & 37,5 & 41,5 \\
$\mathbf{1 5}$ & 37 & 37 & 37,5 & 38 \\
$\mathbf{1 0}$ & 34 & 33 & 35 & 35 \\
$\mathbf{5}$ & 32 & 32 & 31,5 & 32 \\
$\mathbf{P A T E L L A}$ & 31,5 & 31 & 31 & 31 \\
$\mathbf{5}$ & 28,5 & 28,5 & 28 & 28,5 \\
$\mathbf{1 0}$ & 28,5 & 29,5 & 28 & 29 \\
$\mathbf{1 5}$ & 29,5 & 29 & 29 & 29 \\
$\mathbf{2 0}$ & 28,5 & 26 & 28,8 & 27,5 \\
$\mathbf{2 5}$ & 25,8 & 24 & 25,6 & 25 \\
$\mathbf{3 0}$ & 23 & 21,5 & 22,3 & 21 \\
$\mathbf{3 5}$ & 19 & 20 & 19 & 21 \\
MEDİAL & 18 & 18 & 18,5 & 19 \\
MALLEOL & & & & \\
\hline Ölçümler patella & orta hattının 30 cm üstünden itibaren medial malleole dek 5 cm arayla yapılmıştır
\end{tabular}

Tablo 2. Operasyon sonrası uygulanan rehabilitasyondan önce ve sonraki bacak uzunluk ölçümleri

\begin{tabular}{lllll}
\hline & SAĞ $[\mathrm{cm}]$ & & SOL[cm] & \\
\cline { 2 - 5 } & TEDAVI & TEDAVI & TEDAVI & TEDAVI \\
ÖNCESİ & SONRASI & ÖNCESI & SONRASI \\
$\begin{array}{l}\text { UMBLİCUS- } \\
\text { MEDİAL MALLEOL }\end{array}$ & 96 & 96 & 97 & 97 \\
$\begin{array}{l}\text { Si̇AS--MEDİAL } \\
\text { MALLEOL }\end{array}$ & 85,5 & 82,5 & 86,5 & 86,5 \\
\hline
\end{tabular}

SIAS: Spina İliaca Anterior Superior 
Tablo 3. Operasyon sonrası uygulanan rehabilitasyondan önce ve sonraki eklem hareket açıklı̆̆ (EHA) ölçümleri

\begin{tabular}{|c|c|c|c|c|}
\hline & SAĞ & & SOL & \\
\hline & $\begin{array}{l}\text { TEDAVİ } \\
\text { ÖNCESI }\end{array}$ & $\begin{array}{l}\text { TEDAVI } \\
\text { SONRASI }\end{array}$ & $\begin{array}{l}\text { TEDAVI } \\
\text { ÖNCESİ }\end{array}$ & $\begin{array}{l}\text { TEDAVI } \\
\text { SONRASI }\end{array}$ \\
\hline \multicolumn{5}{|l|}{ KALÇA } \\
\hline \multirow[t]{2}{*}{ FLEKSIYYON } & $70^{\circ} \mathrm{A}$ & $90^{\circ} \mathrm{A}$ & $115^{\circ} \mathrm{A}$ & $120^{\circ} \mathrm{A}$ \\
\hline & $80^{\circ} \mathrm{P}$ & $100^{\circ} \mathrm{P}$ & $120^{\circ} \mathrm{P}$ & $130^{\circ} \mathrm{P}$ \\
\hline \multirow{2}{*}{ EKSTANSIYYON } & $10^{\circ} \mathrm{A}$ & $10^{\circ} \mathrm{A}$ & $10^{\circ} \mathrm{A}$ & $10^{\circ} \mathrm{A}$ \\
\hline & $10^{\circ} \mathrm{P}$ & $10^{\circ} \mathrm{P}$ & $15^{\circ} \mathrm{P}$ & $15^{\circ} \mathrm{P}$ \\
\hline \multirow[t]{2}{*}{ ABDÜKSIYYON } & $30^{\circ} \mathrm{A}$ & $45^{\circ} \mathrm{A}$ & $45^{\circ} \mathrm{A}$ & $45^{\circ} \mathrm{A}$ \\
\hline & $45^{\circ} \mathrm{P}$ & $50^{\circ} \mathrm{P}$ & $50^{\circ} \mathrm{P}$ & $50^{\circ} \mathrm{P}$ \\
\hline \multirow[t]{2}{*}{ ADDÜKSIYYON } & $30^{\circ} \mathrm{A}$ & $45^{\circ} \mathrm{A}$ & $30^{\circ} \mathrm{A}$ & $30^{\circ} \mathrm{A}$ \\
\hline & $30^{\circ} \mathrm{P}$ & $45^{\circ} \mathrm{P}$ & $30^{\circ} \mathrm{P}$ & $30^{\circ} \mathrm{P}$ \\
\hline EXTERNAL & $-{ }^{\circ} \mathrm{A}^{*}$ & $25^{\circ} \mathrm{A}$ & $40^{\circ} \mathrm{A}$ & $45^{\circ} \mathrm{A}$ \\
\hline ROTASYON & $-{ }^{\circ} \mathrm{P}^{*}$ & $25^{\circ} \mathrm{P}$ & $45^{\circ} \mathrm{P}$ & $45^{\circ} \mathrm{P}$ \\
\hline İNTERNAL & $10^{\circ} \mathrm{A}$ & $15^{\circ} \mathrm{A}$ & $30^{\circ} \mathrm{A}$ & $45^{\circ} \mathrm{A}$ \\
\hline ROTASYON & $10^{\circ} \mathrm{P}$ & $15^{\circ} \mathrm{P}$ & $40^{\circ} \mathrm{P}$ & $50^{\circ} \mathrm{P}$ \\
\hline \multicolumn{5}{|l|}{ Dìz } \\
\hline \multirow[t]{2}{*}{ FLEKSIYON } & $130^{\circ} \mathrm{A}$ & $130^{\circ} \mathrm{A}$ & $145^{\circ} \mathrm{A}$ & $145^{\circ} \mathrm{A}$ \\
\hline & $140^{\circ} \mathrm{P}$ & $140^{\circ} \mathrm{P}$ & $150^{\circ} \mathrm{P}$ & $150^{\circ} \mathrm{P}$ \\
\hline \multicolumn{5}{|l|}{ AYAK BİLEĞİ } \\
\hline \multirow[t]{2}{*}{ DORSİ FLEKSIYYON } & $40^{\circ} \mathrm{A}$ & $40^{\circ} \mathrm{A}$ & $40^{\circ} \mathrm{A}$ & $40^{\circ} \mathrm{A}$ \\
\hline & $45^{\circ} \mathrm{P}$ & $45^{\circ} \mathrm{P}$ & $45^{\circ} \mathrm{P}$ & $45^{\circ} \mathrm{P}$ \\
\hline PLANTAR & $20^{\circ} \mathrm{A}$ & $20^{\circ} \mathrm{A}$ & $20^{\circ} \mathrm{A}$ & $20^{\circ} \mathrm{A}$ \\
\hline FLEKSIYYN & $20^{\circ} \mathrm{P}$ & $20^{\circ} \mathrm{P}$ & $20^{\circ} \mathrm{P}$ & $20^{\circ} \mathrm{P}$ \\
\hline
\end{tabular}

*Ağrı nedeniyle değerlendirilemedi.

Tablo 4. Operasyon sonrası uygulanan rehabilitasyondan önce ve sonraki kas kuvveti değerlendirmeleri

\begin{tabular}{|c|c|c|c|c|}
\hline & SAĞ & & SOL & \\
\hline & $\begin{array}{l}\text { TEDAVI } \\
\text { ÖNCESİ }\end{array}$ & $\begin{array}{l}\text { TEDAVI } \\
\text { SONRASI }\end{array}$ & $\begin{array}{l}\text { TEDAVI } \\
\text { ÖNCESİ }\end{array}$ & $\begin{array}{l}\text { TEDAVİ } \\
\text { SONRASI }\end{array}$ \\
\hline \multicolumn{5}{|l|}{ KALÇA } \\
\hline FLEKSIYYON & $2+$ & $2+$ & $3+$ & $3+$ \\
\hline EKSTANSIYYON & 2- & $3+$ & $3+$ & $3+$ \\
\hline ABDÜKSIYYN & 2 & $3-$ & $3+$ & $3+$ \\
\hline ADDÜKSIYYON & 2 & 3- & 5 & 5 \\
\hline $\begin{array}{l}\text { EXTERNAL } \\
\text { ROTASYON }\end{array}$ & AĞRILI & $2+$ & 5 & 5 \\
\hline $\begin{array}{l}\text { İNTERNAL } \\
\text { ROTASYON }\end{array}$ & AĞRILI & $2+$ & 5 & 5 \\
\hline \multicolumn{5}{|l|}{ DİZ } \\
\hline FLEKSİYON & $3+$ & $4+$ & $3+$ & 5 \\
\hline EKSTANSIYYON & 5 & 4 & 5 & 5 \\
\hline \multicolumn{5}{|l|}{ AYAK BİLEĞİ } \\
\hline $\begin{array}{l}\text { DORSİ } \\
\text { FLEKSIYYON }\end{array}$ & 5 & 5 & 5 & 5 \\
\hline $\begin{array}{l}\text { PLANTAR } \\
\text { FLEKSIYYON }\end{array}$ & 5 & 5 & 5 & 5 \\
\hline
\end{tabular}


8. haftada tek koltuk değneği ile mobilize olan hastaya havuz içinde yürüyüş egzersizleri (düz yan yürüme, düz-geri yürüme; her biri 5'er dakika) ve jakuzi içinde 5 dakika kalça fleksiyonekstansiyon EHA egzersizleri çalışılmıştır. Kalça ağrısı için $20 \mathrm{dk}$. Transkutanöz elektriksel sinir stimülasyonu (TENS) uygulanmıştır. Kayma tahtasıyla kalça EHA egzersizleri aktif-asistif olarak uygulanmıştır. 10. haftada 3 dakika dirençsiz eliptik bisiklet programa dahil edilirken, EHA çalışmaları kayma tahtası kullanılmadan aktifasistif olarak uygulanmıștır. Havuz içi yürüme egzersizlerinde; 2 set 10 tekrarlı çapraz yan yürüme ve su içinde palet kullanılarak dirençli 4 yönlü kalça izotonik kuvvetlendirme çalışmaları yapılmıştır.

11. ve 12. haftalarda uygun dirençli Theraband (The Hygenic Corporation, Akron, Ohio) ile izotonik egzersizler ağrı sınırında çalışılmıştır. Yürüme bandında 5 dakikalık yürüyüş tedavi programına dahil edilmiştir.

13. haftada tedavi öncesi yapılan değerlendirmeler tekrarlanmıştır (Tablo 1-4).

Sporcunun kalça EHA değerlendirmesinde; sağ kalçada abdüksiyon tam, eksternal rotasyonda 25 derece, internal rotasyonda 5 derece artış, ekstremite uzunluğunda sola göre $3 \mathrm{~cm}$ kısalık saptanmıştır. Kas kuvveti özellikle eksternal rotasyon, internal rotasyon ve abdüksiyonda artış göstermiştir. Sporcunun Trendelenburg yürüyüş paterninde belirgin azalma saptanmıștır.

\section{TARTIŞMA}

Dejeneratif kıkırdak hastalıklarında başlangıçta aksama bulgusu yanında uyluk, kasık ve dizde düşük şiddetli ağrı semptomları görülür. 6 yaş altı çocuklarda başlangıç evrelerinde ağrı kesici kullanma, sıçrama ve koşudan kaçınma hastalığın kontrol altına alınmasında önemlidir. 6 yaş üstü çocuklarda femur başı lateral sütun çökmesi \%50‘yi aştığında cerrahi tedavi gerekir $(6,7)$.

Femur başı avasküler nekrozunda prognostik radyografik bulgular hastalığın başlangıcından 6 ay sonra gözlemlenir $(3,8-10)$. MRG ve pnömoartrografi hastalığın evresi ile ilgili daha kapsamlı bilgi verir. Perfüzyon MRG, femur başı avasküler nekrozu sırasında gerçekleşen vasküler olayların belirlenmesi açısından iyi bir görüntüleme yöntemi olarak kullanılmaktadır $(9,11,12)$.

Olgumuzda iliopsoas tendon rüptürü tanısı ile ameliyat tarihi arasındaki süre 6 aydır. İliopsoas tendon rüptürü nedeniyle femur baş ve boynunu besleyen medial femoral sirkumfleks arterin etkilendiği, bunun da erken başlangıçlı avasküler nekroz hastalığı için etiyolojik zemin hazırladığı düşünülmüştür $(13,14)$ (Şekil 3).

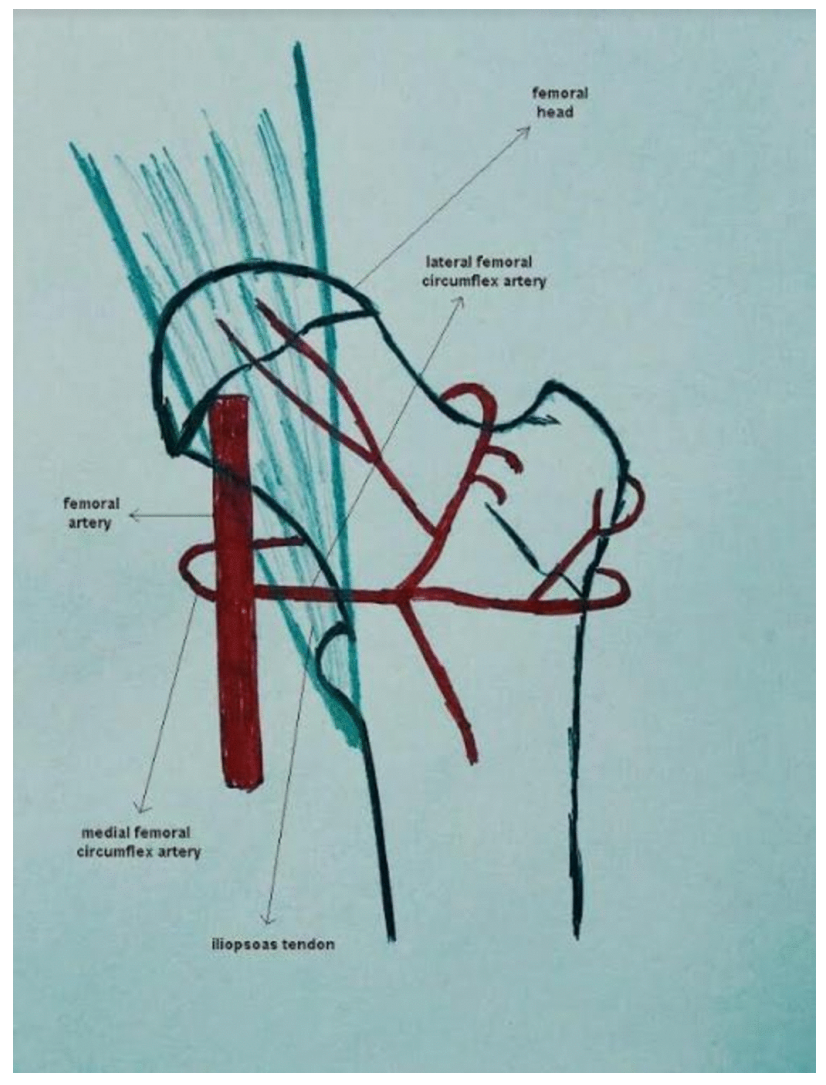

Şekil 3. İliopsoas tendonu ile medial femoral sirkümfleks arterin komşuluğu

İliopsoas tendon rüptürü sonrası avasküler nekroz tanısı ile opere olan olguya rastlanmamıștır.

Kalçada aşırı ve zorlu rotasyon hareketleri eklem kapsülünde gevşekliğe ve labral patolojiye, dolayısıyla atravmatik yaralanmaya neden olabilir. Özellikle golf, artistik patinaj, futbol, bale, 
jimnastik, beyzbol ve hokey sporlarına katılan sporcularda görülebilir (15).

Olgumuzda rehabilitasyon sonrası kalça abdüktörlerinin kuvvet artışı ile Trendelenburg yürüyüşünde düzelme gözlenmiștir.

$\mathrm{Bu}$ olguda ameliyat sonrası mobilizasyonda erken dönemde ödem, ağrı ve ekstremite üzerine ağırlık aktarımının kontrolü için havuz egzersizlerinden yararlanılmış, hareket ve fonksiyondaki gelişim için bu egzersizlerin yararlı olduğu düşünülmüștür.

\section{SONUC}

Genç sporcularda kalça ağrısı değerlendirme ve tedavi yöntemlerine karar verme sürecinde klinik şüphe içeren tüm tablolar gözden geçirilmeli ve uygun tetkik yöntemleri doğru zamanda kullanılmalı ve çok yönlü bir rehabilitasyon programı uygulanmalıdır.

\section{KAYNAKLAR}

1. Anderson KM, Strickland SM, Warren R. Hip and Groin Injuries in Athletes. The Am J Sports Med, 2001;29(4):521-533.

2. Müezzinoğlu S, Sarman H, Memişoğlu K. Approach to Young Hip Pain (Femoroacetabular Impingement and Hip Osteoarthritis). Turkiye Klinikleri J Orthop \& Traumatol-Special Topics 2015;8:25-29.

3. Tuncay İ, Uzer G. Femoroasetabular sıkışmada ayırıcı tanı (Kalça ağrısının ekstra-artiküler nedenleri). TOTBID Dergisi. 2016;15(1):17-22.

4. Hefti F, Clarke NM. The management of Legg-CalvePerthes' disease: is there a consensus? : A study of clinical practice preferred by the members of the $\mathrm{Eu}$ - ropean Paediatric Orthopaedic Society. J Child Orthop, 2007;1(1):19-25.

5. Kim HK. Pathophysiology and new strategies for the treatment of Legg-Calve-Perthes disease. J Bone Joint Surg Am,2012;94(7):659-669.

6. Muratlı HH, Özdemir H. Legg-Calvé-Perthes hastalığının klinik ve radyolojik değerlendirilmesi ve direkt radyografi temelli sinıflama sistemleri. TOTBID Dergisi. 2017;16(1):10-16.

7. Bekmez Ş, Alpaslan AM. Legg-Calvé-Perthes hastalığının doğal seyri. TOTBID Dergisi. 2017;16(1):5-9.

8. Çağlar Ö. Legg-Calvé-Perthes hastalığı sekellerinde total kalça artroplastisi tedavisi ve sonuçları. TOTBID Dergisi. 2017;16(1):66-69.

9. Castaneda P. Can We Solve Legg-Calve-Perthes Disease with Better Imaging Technology? Commentary on an article by Harry K.W. Kim, MD, MS, et al.: "Assessment of Femoral Head Revascularization in LeggCalve-Perthes Disease Using Serial Perfusion MRI".J Bone Joint Surg Am,2016;98(22):1-2.

10. Yılmaz G. Legg-Calvé-Perthes hastalığında cihaz tedavisinin güncel değerlendirmesi. TOTBID Dergisi. 2017;16(1):30-35.

11. Kim HK, Burgess J, Thoveson A.et.al. Assessment of Femoral Head Revascularization in Legg-CalvePerthes Disease Using Serial Perfusion MRI. J Bone Joint Surg Am,2016;98(22):1897-1904.

12. Mazloumi SM, Ebrahimzadeh MH, Kachooei AR. Evolution in diagnosis and treatment of Legg-Calve-Perthes disease. The Arch Bone Jt Surgery. 2014;2(2):86-92.

13. Théron J. Angiography in Legg-Calvé-Perthes disease. Radiology. 1980;135(1):81-92.

14. Tonolini M, Campari A, Bianco R. Common and unusual diseases involving the iliopsoas muscle compartment: spectrum of cross-sectional imaging findings. Abdom Imaging,2012;37(1):118-139.

15. Philippon MJ, Zehms CT, Briggs KK, et. al. Hip instability in the athlete. Oper Tech Sports Med. 2007;25(4):189-194. 